Open Access

\title{
Factors affecting purchasing process of digestate: evidence from an economic experiment on Sicilian farmers' willingness to pay
}

Gioacchino Pappalardo, Roberta Selvaggi ${ }^{*}$ (D, Salvatore Bracco, Gaetano Chinnici and Biagio Pecorino

* Correspondence:

roberta.selvaggi@unict.it

Department of Agriculture, Food and Environment (Di3A), University

of Catania, Via Santa Sofia 98-100,

95123 Catania, Italy

\begin{abstract}
In this study, we evaluate from the perspective of the theory of commitment costs if the level of farmer understanding about digestate attributes could influence the willingness to pay (WTP) for it. For this purpose, we carried out a research on a sample of 223 Sicilian farmers to correlate their WTP for digestate with a set of eight attributes which usually characterise organic soil conditioners. An experimental design was set up so that participants were given different waiting times to decide on their WTP and different levels of information on the attributes of organic soil conditioners. The results highlight a positive WTP, but farmers are strongly influenced by how much information is available on digestate. Without it, farmers' WTP decreases drastically probably due to phenomena correlated to what economic theory calls commitment costs.
\end{abstract}

Keywords: Willingness to pay, Digestate, Experimental auction, Commitment costs

\section{Background}

Digestate is an organic soil conditioner obtained after anaerobic digestion, a biochemical energy conversion process without oxygen. Anaerobic fermentation consists of using microorganisms to break down the organic complexes (fats, proteins, carbohydrates) of plant and animal by-products. Digestate is an optimum organic soil conditioner, rich in nitrogen, phosphorous and potassium. It is more homogeneous compared to the biomass introduced in the anaerobic digesters on which its chemical composition depends (Tambone et al. 2013; Nkoa 2014).

International research (Risberg et al. 2017; Bezzi and Ragazzoni 2014) has shown positive effects from digestate on soil quality. Furthermore, positive effects on soil fertility have been highlighted due to its promptly available nutritional contribution to crops. Digestate also has a long-term effect on soil fertility due to the interaction of its organic fraction with the biochemical dynamics of the soil (Saveyn and Eder 2014). After anaerobic digestion, digestate frequently undergoes separation into a solid fraction used as a manure substitute and a clarified fraction containing nitrogen as ammonia, a fast-acting nutrient for crops (Adubaker et al. 2012).

(c) The Author(s). 2018 Open Access This article is distributed under the terms of the Creative Commons Attribution 4.0 International License (http://creativecommons.org/licenses/by/4.0/), which permits unrestricted use, distribution, and reproduction in any medium, provided you give appropriate credit to the original author(s) and the source, provide a link to the Creative Commons license, and indicate if changes were made. 
Currently, digestate is mainly used in those geographic areas where anaerobic digesters are widespread. In other areas like the Mediterranean basin, despite the high biomass potential available, the number of anaerobic digesters is very low, and the use of digestate as soil conditioner is even more limited (Appel et al. 2016; Manetto et al. 2016; Chinnici et al. 2018). However, increasing the number of anaerobic digestion plants does not seem sufficient to promote the use of digestate as soil conditioner since its chemical/physical properties are yet little known among farmers (Fabbri et al. 2010; Dahlin et al. 2017).

An important condition for widening the digestate market is informing potential users about its chemical/physical properties and its benefits for soil improvement (Dahlin et al. 2015). A lack of data on digestate characteristics could create significant uncertainty among farmers on those benefits. Such uncertainty could also have negative repercussions on the use of digestate as a conditioner and consequently on the willingness to pay (WTP) for digestate notwithstanding the market potential. So, where digestate is little or completely unknown, informing farmers on its benefits might influence their WTP.

In conditions of uncertainty about the value of an asset, the estimate of the WTP as well as the identification of factors that influence the WTP could be affected by the possibility for potential consumers to delay the purchase to acquire future information on the same asset. An interesting approach that economic theory suggests for estimating the WTP of a good little known among potential users is the theory of commitment costs (Zhao and Kling 2000, 2001, 2004).

In such conditions, economic theory suggests that WTP for a good does not solely depend on its intrinsic characteristics but also on other factors such as a good's uncertainty level, the time available to make a purchase decision or the level of withdrawal from a purchase. Zhao and Kling (2000, 2001 and 2004) have deduced that there is a commitment cost associated with a decision to purchase today which forgoes any future option to acquire additional information about a good. Consequently, commitment costs may have significant effects in estimating WTP and its consequent implications.

Despite numerous studies having highlighted the existence of commitment costs (e.g. Johannesson et al. 1999; Lusk 2003; Corrigan 2005; Corrigan et al. 2008; Kling et al. 2013; Bazzani et al. 2017), and their influence on the WTP, a little explored idea regarding identifying the intrinsic characteristics or attributes of an asset which may influence WTP when there are commitment costs or which may contribute to arising them. Knowing little about an assets attributes may give rise to consumer uncertainty on the real value of an asset and consequent delay while further information is sought prior to purchase. In the case of digestate, knowing little about its chemical/physical properties could create farmer uncertainty about its use with consequent repercussions for the WTP (Jones et al. 2010) because of commitment costs.

So, on these premises, the aim of this study is to evaluate from the perspective of the theory of commitment costs if the level of farmer understanding about digestate attributes could influence the WTP. Thus, research was carried out in Sicily (Italy) on a sample of 223 Sicilian farmers to correlate their WTP for digestate with a set of eight attributes which usually characterise organic soil conditioners. An experimental design was set up so that participants were given different waiting times to decide on their WTP and different levels of information on the attributes of organic soil conditioners. In this way, it was possible to determine which digestate attributes influenced their WTP by varying waiting times and information levels. 
Below, there is some brief data on the potential for biogas and digestate in Sicily where our research was conducted.

\section{Background information}

Digestate is part of the biogas chain, an optimum example of circular economy which is a closed-cycle system in which all the products are resources and none are waste (Ammenberg and Roozbeh 2017). Fundamental to closing the cycle is the correct agronomic use of digestate which plays a key role in improving the environmental compatibility of anaerobic digestion with the surrounding environment both in terms of reducing costs and farmers' dependence on industrial fertilisers (Chinnici et al. 2015; Selvaggi et al. 2017; Valenti et al. 2017a). Inspired by 'biofuels done right' (Dale et al. 2010) which refers to integrating anaerobic digestion within the farm without reducing food or fertiliser production, 'biogas done right' term has been coined (Dale et al. 2016).

Due to the 'biogas done right' principle, soils can be employed all year round, crop rotation can be diversified, industrial fertiliser consumption can be reduced by using digestate and renewable energy can be used for the needs of the farm (Cerruto et al. 2016; Valenti et al. 2017b). In Sicily, where this survey has been conducted, the principle of 'biogas done right' has considerable potential to be applied efficiently. In particular, in Sicily, anaerobic digestion can make use of at least three macro-categories of biomass: (1) waste and agricultural and agro-industrial by-products (e.g. olive residues, citrus pulp, whey) which are often treated as wastes; (2) silage from traditional Mediterranean crops in rotation or the second harvest of the main crops chosen according to irrigation availability; (3) silage or plant cuttings from typically Mediterranean bushy crops (e.g. Prickly pear, Opuntia spp) grown on marginal land (Selvaggi et al. 2018a; Valenti et al. 2017c).

\section{Methods}

From April to June 2017, 223 Sicilian farmers (owners or managers) were interviewed, all of whom are involved in decision making regarding farm machinery purchase. They were recruited with the help of local agricultural unions and some Sicilian agricultural cooperatives. Farmers participated in a non-hypothetical experimental auction (Lusk and Shogren 2007; Pappalardo et al. 2016; Wongprawmas et al. 2016; Selvaggi et al. 2018b, 2018c). This type of experiment offers the advantage of providing an incentive for participants to truly reveal their preferences. A second price experimental auction mechanism was designed to elicit WTP for the digestate, and we couple these data with answers from a set of BestWorst (BW) scaling questions that provide a score of the relative importance of various attributes of soil conditioners. By combining the two approaches, we are able to provide an estimate of attributes that can affect WTP for digestate.

In the first step of the study, we recruited farmers for the experimental auction, and at the same time, farmers were asked questions on knowledge of soil conditioners, digestate and demographic information. When the farmers were asked about their willingness to participate in the survey, the interviewers asked some screening questions: 1) Were they owners or managers of the farm? 2) Were they responsible for acquiring farm machinery? 3) Did they use soil conditioners on the farm or would they be interested in doing so? If all the answers were affirmative, those farmers were invited to take part in the survey by meeting up 1 day at a predetermined time to be interviewed using 
the experimental auction method. If even in this case they answered affirmatively, the farmers were invited to fill out a questionnaire asking for some socio-demographic data. In addition, the questionnaire contained questions, formulated with the BW method, on the relative importance of a set of soil conditioners' attributes.

In the second step of the study, the farmers' WTP for digestate was evaluated by a second price experimental auction (Vickrey auction) (Vickrey 1961). Prior to the actual survey, a preliminary survey was carried out on a group of farmers with the double aim of testing the experimental auction protocol and working out the minimum sample size of farmers to interview. The interviews took place in Sicily, in various rural areas, such as to involve farms with varying crops. To incentivise their participation in the survey, each participant was given $€ 10$ of food products.

Because there was no specific literature data on the WTP for digestate in this location, a preliminary study was conducted to help determine sample size, i.e. the number of farmers to include in each experiment treatment. As will be described momentarily, we utilised four experiment treatments. A pre-test was carried out on a sample of 60 Sicilian farmers in four different sessions corresponding to our main treatment effects. Using these data, we found a standard deviation of 5.12, and using a critical effect size of 1.34 (based on differences in means across sessions), we calculated the need of sample size of 56 subjects per treatment to attain $80 \%$ power.

Below, more detail on BW scaling and the second price auction are provided.

\section{Best-worst scaling}

To identify the relative importance of different attributes in the soil conditioner purchasing decision, we used the BW scaling approach, which was originally introduced by Finn and Louviere (1992) and was further developed by Marley and Louviere (2005). Respondents were shown a set of items and were asked to indicate which was the best and which was the worst (or, in this case, which was most and least important). Respondents made several repeated choices where the set of items varies across questions.

In our survey, the items used in BW questions were eight soil conditioners' attributes selected by main literature on the topic (e.g. Pappalardo and Lusk 2016; Dahlin et al. 2017; Hou et al. 2017). The eight attributes and the definition of each are reported in Table 1.

To determine which combination of attributes to present to respondents, we utilised a balanced incomplete block design (BIBD). The eight items (eight attributes) were assigned in groups of five to eight different BW questions (i.e. there were eight BW questions, each containing five of the attributes). To analyse the data obtained from the BW questions, we counted the number of times that a respondent chose an attribute as the most important and subtracted the number of times that the same respondent chose the same attribute as least important across the eight questions. Because each attribute appeared five times, the highest possible score is +5 , and the lowest is -5 .

\section{The experimental auction protocol}

The farmers in the experimental auction were each assigned a personal ID number and given a bag of bidding tickets so as to be able to bid anonymously during the auction experiment. Once the farmers were all seated, the coordinator explained that the experimental auction consisted of various rounds (depending on the treatment) and that 
Table 1 Organic soil conditioners' attributes

\begin{tabular}{ll}
\hline Organic origin & Organic soil conditioners are different from chemical fertilisers \\
Soil fertility & Organic soil conditioners have positive effects on soil fertility \\
Environmental sustainability & Organic soil conditioners production has no environmental impact \\
Local production & Organic soil conditioners are sourced locally \\
Safety & Organic soil conditioners are safe to use because they are not chemical products \\
Price & Organic soil conditioners costs \\
Natural product & $\begin{array}{l}\text { Organic soil conditioners are natural products which contribute to producing } \\
\text { healthier foods }\end{array}$ \\
Microbial activity & $\begin{array}{l}\text { Organic soil conditioners improve microbial activity in the soil because they are } \\
\text { rich in organic substances }\end{array}$ \\
\hline
\end{tabular}

each participant would make various bids to acquire digestate. With all the rounds over, one round would randomly be selected to reveal the auction winner and the second highest bid which would represent the market price (Vickrey auction) (Vickrey 1961). The number of rounds depended on the experiment treatment the farmer had been allocated to but in never treatment, after each round, data on the highest bid and the second highest bid which determined the sale price were provided.

Prior to the experimental auction with the digestate, five test rounds were carried out with an anonymous test product (a $500 \mathrm{~g}$ packet of spaghetti). This auction was only to familiarise the bidders on the protocol. In the real auction, the bidding was for a ton of digestate and consequently the auction winner really bought a ton of digestate paying the second highest price. The auction winner received a coupon for a ton of solid digestate at market price from a known producer. The farmers' bids did not include transport costs from the producer to the auction winner's farm.

\section{Experiment treatments}

The survey was designed to evaluate whether waiting for additional future information on digestate would influence their WTP for it. So, the experiment was designed with four treatments subdividing the farmer sample into four subgroups to which bidders were randomly assigned.

In the first treatment, 'Treatment 1' (T1, 56 members), the experimental auction had only one round, and its members were only provided with basic information on digestate, e.g. where it was produced and how it worked on the soil. Members were also shown a sample of digestate in a container which they could touch and smell. No information on the attributes described above was provided to the participants.

In the second treatment, 'Treatment 2' (T2, 55 members), the experimental auction had five rounds, and bidders were given the same basic information on digestate as in the previous group and shown the same sample of digestate. No information on the attributes described above was provided to the participants.

In the third treatment, 'Treatment 3' (T3, 56 members), the experimental auction had ten rounds, and the bidders were given the same basic information as in the two previous groups as well as the same sample of digestate.

In the final fourth treatment, 'Treatment 4' (T4, 56 members), the experimental auction had ten rounds, but bidders were told that after the first five rounds they would receive additional information on digestate regarding the attributes described above 
(organic origin, soil fertility, etc.). So, the bidders made their first five bids on the basic information received in the three previous treatments. Subsequently, bidders made five more bids having received the additional digestate information.

To avoid any issues of bias or affiliation (Corrigan et al. 2011), in none of the treatments was the winning bid revealed at the end of each round nor the second highest bid representing the market price. Table 2 shows the treatment characteristics.

\section{Results}

\section{Summary statistics}

Table 3 shows the main socio-demographic characteristics of the farmer samples interviewed in the four experiment treatments. The values of Fisher's exact test show that the samples in the four treatments show no differences in terms of gender, age, qualifications, farm income or crop type. In other words, the sample data set is compatible with the null hypothesis $(\mathrm{H} 0)$ of equal means such that the original populations of the four experiment treatments have the same structure and that any observed differences with the sample data is due to chance.

In particular, for the four interviewed groups, men predominate and the prevalent mean ages are between 18-39 and 40-49. The prevalent educational rate is middle school diploma, and the prevalent income of farms run by the interviewees was more than $€ 50,000$ per year. The main farm crops were seed crops and field horticulture.

Table 4 shows the descriptive statistics for WTP in the four treatments. Comparing them, the statistics seem to favour the commitment costs theory and the delay effect to acquire future information. The average bid was highest for $\mathrm{T} 1$ (auction with only one round) at $€ 15.82$; whereas, the lowest average bid was for $\mathrm{T} 3$ (auction with ten rounds) at $€ 5.77$. This result might signify that despite not knowing exactly what might be explained in subsequent rounds, the fact that the farmers had the opportunity to learn through more bids, may have been sufficient to lower their WTP in treatment T3 compared to T1 and T2.

Moreover, T4, the average bid in the first five rounds (T4a) was much lower than in the final five rounds (T4b) having received the additional information on digestate.

Results of the BW analysis applied to attributes of soil conditioners are shown in Table 5. Soil fertility is on average the most important attribute across the four treatments, while environmental sustainability and natural product were the next most important attributes on average. The other attributes with positive scores were microbial activity and organic origin. On the contrary, the least important attributes for farmers are local production, safety and, quite surprisingly, price.

The exact values of the Fischer's test show that the farmer samples in the four treatments show no point differences relative to the importance of the soil conditioners

Table 2 Treatment characteristics

\begin{tabular}{lllll}
\hline & $(\mathrm{T} 1)$ & $(\mathrm{T} 2)$ & $(\mathrm{T})$ & (T4) \\
\hline Auction protocol & Yes & Yes & Yes & Yes \\
Sample to touch and smell & Yes & Yes & Yes & Yes \\
Basic information & Yes & Yes & Yes & Yes \\
Detailed information & No & No & No & Yes \\
Winning bid feedback between rounds & No & No & No & No \\
\hline
\end{tabular}


Table 3 Socio-demographic characteristics

\begin{tabular}{|c|c|c|c|c|c|}
\hline & (T1) (56 units) & (T2) (55 units) & (T3) (56 units) & (T4) (56 units) & Total sample (223 units) \\
\hline \multicolumn{6}{|l|}{ Gender } \\
\hline Male & $92.9 \%$ & $94.5 \%$ & $94.6 \%$ & $96.4 \%$ & $94.6 \%$ \\
\hline Female & $7.1 \%$ & $5.5 \%$ & $5.4 \%$ & $3.6 \%$ & $5.4 \%$ \\
\hline \multicolumn{6}{|c|}{ Fisher's exact test $p$ value 0.613} \\
\hline \multicolumn{6}{|l|}{ Age } \\
\hline $18-39$ & $32.1 \%$ & $38.2 \%$ & $37.5 \%$ & $25.0 \%$ & $33.2 \%$ \\
\hline $40-49$ & $32.1 \%$ & $29.1 \%$ & $39.3 \%$ & $44.6 \%$ & $36.3 \%$ \\
\hline $50-65$ & $30.4 \%$ & $21.8 \%$ & $16.1 \%$ & $25.0 \%$ & $23.3 \%$ \\
\hline$>65$ & $5.4 \%$ & $10.9 \%$ & $7.1 \%$ & $5.4 \%$ & $7.2 \%$ \\
\hline \multicolumn{6}{|c|}{ Fisher's exact test $p$ value 0.459} \\
\hline \multicolumn{6}{|l|}{ Educational rate } \\
\hline Elementary school & $3.6 \%$ & $9.1 \%$ & $7.1 \%$ & $3.6 \%$ & $5.8 \%$ \\
\hline Middle school & $28.6 \%$ & $29.1 \%$ & $39.3 \%$ & $46.4 \%$ & $35.9 \%$ \\
\hline High school Diploma & $35.7 \%$ & $38.2 \%$ & $39.3 \%$ & $30.4 \%$ & $35.9 \%$ \\
\hline Degree & $30.4 \%$ & $21.8 \%$ & $14.3 \%$ & $17.9 \%$ & $21.1 \%$ \\
\hline Other & $1.8 \%$ & $1.8 \%$ & $0.0 \%$ & $1.8 \%$ & $1.3 \%$ \\
\hline \multicolumn{6}{|c|}{ Fisher's exact test $p$ value 0.407} \\
\hline \multicolumn{6}{|l|}{ Farm income (€/year) } \\
\hline Less than 10,000 & $14.3 \%$ & $12.7 \%$ & $16.1 \%$ & $8.9 \%$ & $13.0 \%$ \\
\hline $10,000-19,999$ & $28.6 \%$ & $27.3 \%$ & $32.1 \%$ & $23.2 \%$ & $27.8 \%$ \\
\hline $20,000-39,999$ & $25.0 \%$ & $25.5 \%$ & $30.4 \%$ & $19.6 \%$ & $25.1 \%$ \\
\hline $40,000-49,999$ & $5.4 \%$ & $1.8 \%$ & $8.9 \%$ & $1.8 \%$ & $4.5 \%$ \\
\hline$>50,000$ & $26.8 \%$ & $32.7 \%$ & $12.5 \%$ & $46.4 \%$ & $29.6 \%$ \\
\hline \multicolumn{6}{|c|}{ Fisher's exact test $p$ value 0.732} \\
\hline \multicolumn{6}{|l|}{ Crops } \\
\hline Seed & $53.6 \%$ & $43.6 \%$ & $69.6 \%$ & $42.9 \%$ & $52.5 \%$ \\
\hline Fruit & $7.1 \%$ & $9.1 \%$ & $10.7 \%$ & $10.7 \%$ & $9.4 \%$ \\
\hline Citrus & $8.9 \%$ & $7.3 \%$ & $5.4 \%$ & $8.9 \%$ & $7.6 \%$ \\
\hline Livestock & $10.7 \%$ & $12.7 \%$ & $1.8 \%$ & $1.8 \%$ & $6.7 \%$ \\
\hline Field Horticulture & $17.9 \%$ & $23.6 \%$ & $1.8 \%$ & $35.7 \%$ & $19.7 \%$ \\
\hline $\begin{array}{l}\text { Greenhouse } \\
\text { Horticulture }\end{array}$ & $0.0 \%$ & $1.8 \%$ & $5.4 \%$ & $0.0 \%$ & $1.8 \%$ \\
\hline Other & $1.8 \%$ & $1.8 \%$ & $5.4 \%$ & $0.0 \%$ & $2.2 \%$ \\
\hline \multicolumn{6}{|c|}{ Fisher's exact test $p$ value 0.370} \\
\hline
\end{tabular}

Table 4 Willingness to pay for digestate (Euro/ton) per treatment

\begin{tabular}{llllll}
\hline Treatment & $\begin{array}{l}\text { Mean } \\
{[€ / \mathrm{t}]}\end{array}$ & $\begin{array}{l}\text { Median } \\
{[€ / \mathrm{t}]}\end{array}$ & $\begin{array}{l}\text { Minimum } \\
{[€ / \mathrm{t}]}\end{array}$ & $\begin{array}{l}\text { Maximum } \\
{[€ / \mathrm{t}]}\end{array}$ & $\begin{array}{l}\text { St- } \\
\text { dev }\end{array}$ \\
\hline T1 & 15.82 & 10.00 & 0.00 & 80.00 & 16.89 \\
T2 & 13.72 & 10.00 & 0.00 & 64.00 & 12.76 \\
T3 & 5.77 & 2.87 & 0.00 & 53.00 & 8.63 \\
T4 & 11.09 & 9.63 & 0.00 & 53.00 & 9.31 \\
- T4a & 6.27 & 2.95 & 0.00 & 28.00 & 6.58 \\
- T4b & 15.92 & 11.65 & 0.00 & 78.00 & 15.10 \\
\hline
\end{tabular}


Table 5 Statistics of best-worst scores for soil conditioners' attributes

\begin{tabular}{|c|c|c|c|c|}
\hline & $\mathrm{T} 1$ & $\mathrm{~T} 2$ & T3 & T4 \\
\hline Organic origin & 0.46 & 0.67 & 0.11 & -0.16 \\
\hline \multicolumn{5}{|c|}{ Fisher's exact test $p$ value $=0.0801$} \\
\hline Soil fertility & 1.66 & 1.36 & 1.71 & 1.61 \\
\hline \multicolumn{5}{|c|}{ Fisher's exact test $p$ value $=0.7682$} \\
\hline Environmental sustainability & 0.79 & 0.65 & 0.27 & 0.34 \\
\hline \multicolumn{5}{|c|}{ Fisher's exact test $p$ value $=0.4410$} \\
\hline Local production & -1.43 & -0.82 & -1.16 & -0.57 \\
\hline \multicolumn{5}{|c|}{ Fisher's exact test $p$ value $=0.1297$} \\
\hline Safety & -0.57 & -1.00 & -0.88 & -0.63 \\
\hline \multicolumn{5}{|c|}{ Fisher's exact test $p$ value $=0.5412$} \\
\hline Price & -0.66 & -0.60 & -0.07 & -1.09 \\
\hline \multicolumn{5}{|c|}{ Fisher's exact test $p$ value $=0.2757$} \\
\hline Natural product & 0.48 & 0.55 & 0.27 & 0.77 \\
\hline \multicolumn{5}{|c|}{ Fisher's exact test $p$ value $=0.2067$} \\
\hline Microbial activity & 0.21 & 0.33 & 0.34 & 0.61 \\
\hline Fisher's exact test $p$ value $=$ & & & & \\
\hline
\end{tabular}

attributes with the exception of the 'organic origin' attribute which was evaluated negatively only by the farmers who participated in treatment $\mathrm{T} 4$. This highlights that in all treatments, farmers had similar opinions on all the researched attributes. This homogeneity makes the results very comparable.

\section{Effect of soil conditioners' attributes on farmers WTP for digestate}

To estimate effects of soil conditioners' attributes on WTP for the digestate, four OLS regressions were estimated in which the WTP for the digestate was specified as a function of the BW scores. The dependent variables in the four OLS regressions were as follows: 1) WTP for the digestate with no delay and without information on digestate's attributes (T1), 2) WTP for the digestate with average delay and without information on digestate's attributes (T2), 3) WTP for the digestate with long delay and without information on digestate's attributes (T3), 4) WTP for the digestate with delayed information (T4). The independent variables in each regression are the scores related to the eight attributes obtained through the BW scaling. The score of the attribute "local production' was omitted to avoid perfect collinearity (the sum of all BW values is always zero by construction).

The regressions showed which digestate attributes influence WTP by varying wait times and the possibility of acquiring further information. Table 6 shows that WTP for digestate is influenced by variables according to treatment. In treatment T1, where participants bid without a wait time nor with any information on the digestate, their WTP is significantly negative only for the 'security' attribute. In treatment T2, when participants could make five bids, WTP was influenced not only by 'security' but also by 'natural product' and 'microbial activity'.

'Environmental sustainability' and 'price' were statistically significant in T3 where participants had long wait times to decide on their WTP (ten bids). 
Table 6 OLS regression of attributes affecting willingness to pay for digestate

\begin{tabular}{llllll}
\hline Attributes included in the models & T1 & T2 & T3 & T4a & T4b \\
\hline Const. & 11.774 & 9.4533 & 2.8795 & 3.9313 & 13.417 \\
& $(0.0001)^{* * *}$ & $(0.0001)^{* * *}$ & $(0.0001)^{* * *}$ & $(0.0002)^{* * *}$ & $(0.0000)^{* * *}$ \\
Organic origin & 0.4975 & 0.3214 & -0.1993 & -0.2564 & -2.6421 \\
& $(0.4212)$ & $(0.7042)$ & $(0.5890)$ & $(0.6120)$ & $(0.0084)^{* * *}$ \\
Soil fertility & 0.9465 & -0.2672 & 0.3260 & -0.1544 & -2.2206 \\
& $(0.3159)$ & $(0.6540)$ & $(0.2872)$ & $(0.7044)$ & $(0.0001)^{* * *}$ \\
Environmental sustainability & -0.4454 & -1.2449 & -0.4731 & -0.57858 & -2.1899 \\
& $(0.6843)$ & $(0.1311)$ & $(0.0629)^{*}$ & $(0.1294)$ & $(0.0002)^{* * *}$ \\
Safety & -1.8563 & -2.8498 & -0.6556 & -0.4310 & -3.1472 \\
& $(0.0859)^{*}$ & $(0.0016)^{* * *}$ & $(0.2117)$ & $(0.3795)$ & $(0.0023)^{* * *}$ \\
Price & -0.5677 & -0.2078 & -0.7885 & -0.5360 & -1.8548 \\
& $(0.4405)$ & $(0.7163)$ & $(0.0015)^{* * *}$ & $(0.2100)$ & $(0.0046)^{* * *}$ \\
Natural product & 0.3112 & 3.1440 & 0.4772 & 1.1918 & -0.3263 \\
& $(0.7855)$ & $(0.0028)^{* * *}$ & $(0.3047)$ & $(0.0289) * *$ & $(0.7267)$ \\
Microbial activity & 0.1671 & -0.7236 & 0.2637 & -0.0036 & -1.0926 \\
& $(0.8206)$ & $(0.0894)^{*}$ & $(0.5272)$ & $(0.9878)$ & $(0.0170)^{* *}$ \\
& $R^{2}=0.23$ & $R^{2}=0.75$ & $R^{2}=0.37$ & $R^{2}=0.30$ & $R^{2}=0.40$ \\
& Adjusted & Adjusted & Adjusted & Adjusted & Adjusted \\
& $R^{2}=0.12$ & $R^{2}=0.72$ & $R^{2}=0.27$ & $R^{2}=0.20$ & $R^{2}=0.31$ \\
\hline
\end{tabular}

Values in the brackets are $p$ values: ${ }^{*} 10 \%$; ${ }^{*} 5 \% ;{ }^{* *} 1 \%$

Finally, in T4, there were significant differences in the attributes which influence WTP. In the first five rounds (T4a), when participants had little detailed information on digestate, only 'natural product' was significant. By contrast, in the last five rounds (T4b), when participants had extra information on digestate, WTP was statistically influenced by all the attributes except by 'natural product'.

\section{Discussion}

The results of our study show above all farmers' WTP for digestate as an organic soil conditioner for their farms. It confirms therefore that which has been highlighted by other studies-farmers' interest in digestate (Saveyn and Eder 2014; Dahlin et al. 2017). This is a positive result which can help grow the environmental sustainability of anaerobic digestion on farms and increase income from biogas, traditionally dependent on state subsidies.

Furthermore, the studies' results confirm previous studies on the existence of commitment costs and their influence on the WTP for a certain asset (Lusk 2003; Bazzani et al. 2017). In fact, a greater WTP for digestate was obtained when the participants were provided with detailed information on its attributes (treatment $4 \mathrm{~b}$ ).

This signifies that the information provided might have diminished the degree of participant uncertainty about digestate attributes, lowering commitment costs and consequently increasing the WTP. Moreover, confirming the results of previous studies (Corrigan 2005; Corrigan et al. 2008; Kling et al. 2013), the WTP values obtained in this study change according to how much time participants had to come to a purchase decision. In particular, the WTP for digestate was lowest when participants had more time for their bids (T3); whereas, it was highest when there was least decision time (T1).

Nevertheless, our studies' results go beyond those of the existing literature because in addition to highlighting commitment costs in the purchase process of digestate, the research tried to identify which digestate attributes are connected with the WTP by changing wait times and the level of available information. Identifying such attributes in 
different contexts might contribute to explaining why commitment costs arise in the digestate purchasing process.

Our study highlighted that the digestate attributes, which influence the WTP probably due to commitment costs, change according to the influx of extra information. With extra information on digestate, nearly all the attributes influenced, even if negatively, WTP. This has important implications for biogas and digestate since notwithstanding their undoubted interest, the farmers have a negative perception of the organic origin of digestate, the environmental sustainability of the production process, security, price and its effects on soil fertility.

These last results were not presented by T1, T2 or T3, which might lead to a misinterpretation regarding the factors influencing the purchase of digestate. To reinforce and make more widespread the use of digestate as a soil improver for farms, the causes should be investigated into the commitment costs factor to overcome farmers' perplexities about the properties of digestate. The lack of specific information on digestate characteristics significantly lowers their WTP due to commitment costs about the real characteristics and benefits for agricultural soil.

\section{Conclusions}

In this study, the WTP for digestate as an organic soil conditioner for their farms was evaluated for a sample of Sicilian farmers. The results highlight a positive WTP, but farmers are strongly influenced by how much information is available on digestate. Without it, farmers' WTP decreases drastically probably due to phenomena correlated to what economic theory calls commitment costs.

Results of our study could have important implications for organic soil conditioner market and biogas sector. Understanding attributes affecting farmers' WTP for digestate can promote the market of digestate among farmers with positive effects on soil quality and soil fertility due to its promptly available nutritional contribution to crops. Moreover, our results could be important for biogas industry since digestate is currently mainly used in those geographic areas where anaerobic digesters are widespread. Understanding factors affecting purchasing process of digestate can boost the diffusion of digestate also in other areas like the Mediterranean basin where high quantities of biomasses are available, but the use of digestate as soil conditioner is even limited since it is not well-known among farmers. Moreover, since the profitability of digesters is traditionally dependent on state subsidies, opening new markets to commercialise digestate could create new income opportunities for digester managers especially in those areas where the spread of anaerobic digesters is still low.

The authors are aware of certain limits in this study such as the location where the research was carried out or the number and appropriateness of attributes of the organic soil conditioners considered. Future research could further explore other digestate attributes which could influence WTP or verify the analysis model we adopted in other locations. However, our results highlight a positive perception of digestate by farmers which may have important implications for both the organic soil conditioner market as well as for the biogas industry within which digestate is a significant output. 


\section{Acknowledgements}

A special thank goes to prof. Jayson Lusk for his support in the design of the experiment treatments and for the suggestions and support in the data analysis. The authors want to thank the anonymous reviewers for their insightful comments. Any remaining errors are the responsibility of the authors.

\section{Funding}

This research was conducted within the framework of the research projects INNOBIOMED (CUP E62F15000380005), financially supported by Italian Ministry of Agriculture (MIPAAF) and 'Agronomic Innovations and Economic Analysis of Biomass Production for Energy and Economic Valuation of Natural Capital' (5A722192115), financially supported by University of Catania (Italy).

\section{Availability of data and materials}

All data were acquired and elaborated by the authors. Data supporting the research are available by requesting to the authors.

\section{Authors' contributions}

The work is the result of the full cooperation of all authors. However, the first author wrote all the section 'Methods' and the paragraph 'Summary statistics'; second author (corresponding author) wrote paragraphs 'Background information', 'Effect of soil conditioners' attributes on farmers WTP for digestate' and the section 'Discussion'; fourth author wrote the principal description of the section 'Background'; third and fifth authors wrote the section 'Conclusions', and they supervised the work. All the authors read and approved the final manuscript.

\section{Competing interests}

The author declares that he/she has no competing interests.

\section{Publisher's Note}

Springer Nature remains neutral with regard to jurisdictional claims in published maps and institutional affiliations.

Received: 9 November 2017 Accepted: 24 July 2018

Published online: 05 September 2018

\section{References}

Adubaker J, Risberg K, Pell M (2012) Biogas residues as fertilisers - effects on wheat growth and soil microbial activities. Appl Energy 99:126-134

Ammenberg J, Roozbeh F (2017) Assessment of feedstocks for biogas production, part II - results for strategic decision making. Resour Conserv Recycl 122:388-404

Appel F, Ostermeyer-Wiethaup A, Balmann A (2016) Effects of the German renewable energy act on structural change in agriculture - the case of biogas. Util Policy 41:172-182

Bazzani C, Caputo V, Nayga RM, Canavari M (2017) Testing commitment cost theory in choice experiments. Econ Inq 55(1):383-396

Bezzi G, Ragazzoni A (2014) Digestato: opportunità e vantaggi negli impieghi in agricoltura. Edizioni L'Informatore Agrario, prima edizione ottobre 2014

Cerruto E, Selvaggi R, Papa R (2016) Potential biogas production from by-products of citrus industry in Sicily. Quality Access to Success 17(S1):251-258

Chinnici G, D'Amico M, Pecorino B (2015) Assessment and prospects of renewable energy in Italy. Quality Access to Success 16(S1):126-134

Chinnici G, Selvaggi R, D'Amico M, Pecorino B (2018) Assessment of the potential energy supply and biomethane from the anaerobic digestion of agro-food feedstocks in Sicily. Renew Sust Energ Rev 82:6-13

Corrigan J, Drichoutis A, Lusk J, Nayga RM, Rousu M (2011) Repeated rounds with price feedback in auction experiment valuation: an adversarial collaboration. Am J Agric Econ 94(1):97-115

Corrigan JR (2005) Is the auction experiment a dynamic market? Environ Resour Econ 31(1):35-45

Corrigan JR, Kling CL, Zhao J (2008) Willingness to pay and the cost of commitment: an empirical specification and test. Environ Resour Econ 40(2):285-298

Dahlin J, Herbes C, Nelles M (2015) Biogas digestate marketing: qualitative insights into the supply side. Resour Conserv Recycl 104(A):152-161

Dahlin J, Nelles M, Herbes C (2017) Biogas digestate management: evaluating the attitudes and perceptions of German gardeners towards digestate-based soil amendments. Resour Conserv Recycl 118:27-38

Dale BE, Bals BD, Kim S, Eranki P (2010) Biofuels done right: land efficient animal feeds enable large environmental and energy benefits. Environ Sci Technol 44(22):8385-8389

Dale BE, Sibilla F, Fabbri C, Pezzaglia M, Pecorino B, Veggia E et al (2016) Biogasdoneright ${ }^{\text {TM. }}$ an innovative new system is commercialized in Italy. Biofuels Bioprod Biorefin 10:341-345

Fabbri C, Soldano M, Piccinini S (2010) L'agricoltore crede nel biogas e i numeri lo confermano. L'Informatore Agrario, n. $30 / 2010$

Finn A, Louviere JJ (1992) Determining the appropriate response to evidence of public concern: the case of food safety. J Public Policy Market 11(2):12-25 http://www.jstor.org/stable/30000270

Hou J, Li M, Mao X, Hao Y, Ding J, Liu D et al (2017) Response of microbial community of organic-matter-impoverished arable soil to long-term application of soil conditioner derived from dynamic rapid fermentation of food waste. PLoS One 12(4):e0175715. https://doi.org/10.1371/journal.pone.0175715

Johannesson M, Blomquist GC, Blumen-schein K, Johansson P, Liljas B, O'Connor RM (1999) Calibrating hypothetica willingness to pay responses. J Risk Uncertain 8:21-23 
Jones N, Evangelinos K, Halvadakis CP, losifides T, Sophoulis CM (2010) Social factors influencing perceptions and willingness to pay for a market-based policy aiming on solid waste management. Resour Conserv Recycl 54(9):533-540

Kling CL, List JA, Zhao J (2013) A dynamic explanation of the willingness to pay and willingness to accept disparity. Econ Inq 51(1):909-921

Lusk JL (2003) An experimental test of commitment cost theory. Am J Agric Econ 85(5):1316-1322

Lusk JL, Shogren JF (2007) Auction experiments, methods and applications in economic and marketing research. Cambridge University Press, Cambridge

Manetto G, Pecorino B, Selvaggi R (2016) Sustainability of a consortial anaerobic fermentation plant in Sicily. Quality Access to Success 17:106-112

Marley AAJ, Louviere JJ (2005) Some probabilistic models of best, worst, and best-worst choices. J Math Psychol 49:464-480

Nkoa R (2014) Agricultural benefits and environmental risks of soil fertilization with anaerobic digestates: a review. Agron Sustain Dev 34(2):473-492

Pappalardo G, Carnemolla TM, La Via G (2016) Factors affecting purchasing process of functional foods. Quality Access to Success 17:229-235

Pappalardo G, Lusk JL (2016) The role of beliefs in purchasing process of functional foods. Food Qual Prefer 53:151-158

Risberg K, Cederlund H, Pell M, Arturson V, Schnürer A (2017) Comparative characterization of digestate versus pig slurry and cow manure - chemical composition and effects on soil microbial activity. Waste Manag 61:529-538

Saveyn H, Eder P (2014) End-of-waste criteria for biodegradable waste subjected to biological treatment (compost \& digestate): technical proposals Luxembourg. JRC Scientific and Policy Reports

Selvaggi R, Chinnici G, Pappalardo G (2018b) Estimating willingness to pay for digestate: evidence from an economic experiment from Sicilian farmers. Quality Access to Success 19(S1):489-493

Selvaggi R, Parisi M, Pecorino B (2017) Economic assessment of cereal straw management in Sicily. Quality Access to Success 18(S2):409-415

Selvaggi R, Valenti F, Pappalardo G, Rossi L, Bozzetto S et al (2018a) Sequential crops for food, energy and economic development in rural areas: the case of Sicily. Biofuels Bioprod Biorefin 12(1):22-28

Selvaggi R, Verduci M, Pecorino B (2018c) Estimate of willingness to pay for Etna red wines: evaluation of the existence of an experiential component in purchase phase. Quality Access to Success 19(S1):494-499

Tambone F, Adani F, Gigliotti G, Volpe D, Fabbri C, Provenzano MR (2013) Organic matter characterization during the anaerobic digestion of different biomasses by means of CPMAS 13C NMR spectroscopy. Biomass Bioenergy 48:111-120

Valenti F, Arcidiacono C, Chinnici G, Cascone G, Porto SMC (2017b) Quantification of olive pomace availability for biogas production by using a GIS-based model. Biofuels Bioprod Biorefin 11(5):784-797

Valenti F, Porto SMC, Chinnici G, Cascone G, Arcidiacono C (2017c) Assessment of citrus pulp availability for biogas production by using a GIS-based model: the case study of an area in southern Italy. Chem Eng Trans 58:529-534

Valenti F, Porto SMC, Chinnici G, Selvaggi R, Cascone G et al (2017a) Use of citrus pulp for biogas production: a GIS analysis of citrus-growing areas and processing industries in South Italy. Land Use Policy 66:151-161

Vickrey W (1961) Counterspeculation, auctions and competitive sealed tenders. J Financ 16:8-37

Wongprawmas R, Pappalardo G, Canavari M, Pecorino B (2016) Willingness-to-pay for multiple units of eco-friendly wheat-derived products: results from open-ended choice experiments. J Food Prod Mark 22(6):658-682

Zhao J, Kling C (2000) Willingness-to-pay, compensating variation, and the cost of commitment. Working paper. lowa State University. http://ageconsearch.umn.edu/bitstream/18357/1/wp000251.pdf

Zhao J, Kling CL (2001) A new explanation for the WTPNTA disparity. Econ Lett 73(3):293-300

Zhao J, Kling CL (2004) Willingness to pay, compensating variation, and the cost of commitment. Econ Inq 42(3):503-517

\section{Submit your manuscript to a SpringerOpen ${ }^{\circ}$ journal and benefit from:}

- Convenient online submission

- Rigorous peer review

- Open access: articles freely available online

High visibility within the field

- Retaining the copyright to your article

Submit your next manuscript at $\mathbf{s p r i n g e r o p e n . c o m ~}$ 